\title{
ESTUDANTES DE LICENCIATURA NO BRASIL: REPRESENTAÇÕES SOCIAIS SOBRE O "SER PROFESSOR NO FUTURO"
}

\author{
Estudiantes de licenciatura en Brasil: representaciones sociales acerca de \\ 'ser un maestro en el futuro'
}

Teacher's graduation courses students in Brazil: social representations about 'being a teacher in the future'

\author{
Romilda Teodora Ens* \\ Jaqueline Salanek de Oliveira Nagel** \\ Thalita Vianna de Lima*** \\ Cassiano Roberto Nascimento Ogliari****
}

https://doi.org/10.38117/2675-181X.formov2020.v2i2n4.416-438

\section{RESUMO}

O presente artigo tem como objetivo analisar a relação entre políticas de formação docente para a Educação Básica e as Representações Sociais (RS) de estudantes de licenciatura sobre o futuro de "ser professor", com o pressuposto de que o atual contexto político, social, econômico e ideológico passa por tensões. Fundamentase na Teoria das Representações Sociais e na Teoria do Núcleo Central, assim como nas políticas educacionais, para apreender como estão estruturadas as RS sobre o futuro profissional desses estudantes de licenciatura. Trata-se de uma pesquisa de abordagem qualitativa, que faz opção pela hermenêutica e apresenta uma análise prototípica, com uso do software Evoc (2005) e interpretação da Classificação Hierárquica Descendente (CHD), utilizando-se também do software Iramuteq (2009), para que sejam estudadas as representações desses estudantes. Os resultados indicam que os estudantes ancoram suas representações nas constantes políticas que definem sua formação e o futuro de seu complexo trabalho.

PALAVRAS CHAVE: Política de Formação Docente; Estudantes de Licenciatura; Educação Básica; Representações Sociais.

\section{RESUMEN}

Este artículo tiene como objetivo analizar la relación entre las políticas de educación docente para la Educación Básica y las Representaciones Sociales (RS) 
de los estudiantes de licenciatura sobre el futuro de "ser un maestro", con el supuesto de que el contexto político, social, económico e ideológico actual pasa por tensiones. Se basa en la Teoría de las Representaciones Sociales y la Teoría del Núcleo Central, así como en las políticas educativas, para aprender cómo se estructura la RS sobre el futuro profesional de estos estudiantes de pregrado. Es una investigación cualitativa, que hace una opción. por hermenéutica y presenta un análisis prototípico, utilizando el software Evoc (2005) y la interpretación de la Clasificación Jerárquica Descendente (CJD), también utilizando el software Iramuteq (2009), para que se estudien las representaciones de estos estudiantes. Los resultados indican que los estudiantes anclan sus representaciones en las políticas constantes que definen su educación y el futuro de su trabajo complejo.

PALABRAS CLAVE: Política de formación docente; Estudiantes de licenciatura Educación básica; Representaciones sociales.

\section{ABSTRACT}

This article aims to analyze the relationship between teacher education policies for Basic Education and the Social Representations (SR) of teacher's graduation courses students about the future of "being a teacher", with the assumption that the current political, social, economic and ideological context goes through tensions. It is based on the Social Representations Theory and the Central Nucleus Theory, as well as on the educational policies, to learn how the SR about the professional future of these students are structured. It is a qualitative research, which makes an option by hermeneutics and presents a prototypical analysis, using the Evoc software (2005) and Descending Hierarchical Classification (DHC) interpretation, also using the Iramuteq software (2009), so that the representations of these students are studied. The results indicate that students anchor their representations upon the constant policies that define their education and the future of their complex work.

KEYWORDS: Teacher Education Policy; Undergraduate teacher-students; Basic education; Social Representations.

\section{Introdução}

As condições atuais de trabalho e formação na área de licenciatura levam-nos a refletir acerca das mais diferentes expectativas que os estudantes depositam em relação ao seu futuro profissional. Vivemos em uma época na qual o presente "[...] é vivenciado de forma muito diferente conforme o lugar ocupado na sociedade" (HARTOG, 2015, p. 14), pois a lógica de mercado impulsiona um panorama cercado de incertezas, diversidades e desigualdades, com políticas educacionais brasileiras para a formação de 
ESTUDANTES DE LICENCIATURA NO BRASIL: representações sociais sobre o "ser professor no futuro"

docentes que impulsionam o desencanto e a autoestima baixa dos alunos que buscam essa formação.

Ao discutir a formação de professores, reforçamos que a dicotomia existente entre o mercado de trabalho e a realização profissional permeia todo o processo do "ser professor", à qual se soma a complexa rede dos aspectos sociais, culturais, financeiros e políticos que definem essa formação e profissão. O conceito de "ser professor" sofreu um alargamento de seu trabalho, ao mesmo tempo em que a formação do professor é menor e polivalente, tendo como consequência a desintelectualização do professor para a educação básica no Brasil, somados a não valorização e não reconhecimento social. Aspectos esses que justificam questionarmos como os estudantes de licenciatura percebem seu futuro como professor, ou seja, representam o "ser professor no futuro". A partir destas reflexões, questionamos: "As políticas de formação do professor consideram as perspectivas dos licenciandos sobre seu futuro profissional?". Pois, temos como pressuposto que as ancoragens das representações sociais dos estudantes de licenciatura têm nas políticas educacionais um dos macroreguladores de suas representações sociais.

Para responder a essa questão, tomamos como aporte teórico a Teoria das Representações Sociais (TRS) e as políticas educacionais para analisar a percepção sobre o futuro esperado por estudantes de licenciatura, pois ser professor, como afirma Dotta (2006, p. 73), é, antes, ser “[...] aquele que participa da construção da história futura do aluno enquanto pessoa e profissional". Com base nas questões apontadas, podemos dizer que o grande desafio da profissão docente consiste em um processo de desenvolvimento profissional, uma vez que, de acordo com André (2010, p. 176), "a formação docente tem que ser pensada como um aprendizado profissional ao longo da vida, o que implica envolvimento dos professores em processos intencionais e planejados", a partir de políticas que promovam este desenvolvimento.

E, nesse entrelaçamento, futuro, como destaca Hartog (2015), precisa ser pensado a partir de um paralelo tecido entre os tempos "antigos" e "modernos", uma vez que o século XX tornou-se "[...] mais futurista do que presentista, [... e] terminou mais presentista do que futurista" (p. 140), ao valorizar mais o imediato. Muitas vezes, a reflexão sobre o trabalho do professor no espaço/tempo da escola acontece de forma presentista, orientada pela formação polivalente dos licenciandos. Em conformidade com Evangelista e Triches (2012), busca-se por essa formação polivalente um "superprofessor", capaz de resolver os problemas da escola e, também, os que estão envoltos em um âmbito maior, além dos muros da escola. Pensar sobre o trabalho do professor é pensar nas regulações definidas pelas políticas educacionais e na ação dessas políticas, pois este é um processo complexo, no qual: 
[...] a pessoa que põe em prática as políticas tem que converter/transformar essas duas modalidades, entre a modalidade da palavra escrita e a da ação, e isto é algo difícil e desafiador de se fazer. [...] A prática é composta de muito mais do que a soma de uma gama de políticas e é tipicamente investida de valores locais e pessoais e, como tal, envolve a resolução de, ou luta com, expectativas e requisitos contraditórios - acordos e ajustes secundários fazem-se necessários (BALL ${ }^{1}, 2009$, p. 305).

A política, quando colocada em prática, molda-se de acordo com o contexto em que está inserida, a partir da ação e do discurso daquele que a executa. Assim, concordamos com Moscovici (2003, p. 314), quando afirma que "[...] é difícil saber como uma ideia nasce na mente de alguém”, pois “[...] há sempre uma transfertilização de conjunturas, interesses e intenções" responsável por delinear o formato dessa política no âmbito escolar.

No uso da expressão “transfertilização”, Moscovici (2003) apoiou-se em Frankel² (1987), para o qual não há uma transferência de forças sociais, econômicas e políticas, mas, sim, de diferentes conjuntos de interesse global ou local que se entrecruzam com valores, crenças ou padrões de comportamento, culturas de determinados grupos ou indivíduos na produção das políticas educacionais.

No contexto dos efeitos das políticas, situam-se, entre outros, os estudos das representações sociais como fontes para se pensar acerca das políticas educacionais, os quais, além de situarem os desafios, buscam soluções para compreender os processos políticos, históricos e sociais, por exemplo, os que decorrem de políticas governamentais para a formação de professores.

O caminho da formação de professores é permeado por desafios que nos levam a refletir como as políticas de formação estão definidas e se concretizam na prática, por meio das representações sociais daqueles que estão envolvidos no processo. $\mathrm{O}$ intuito desse estudo é relacionar as políticas de formação de professores, as representações sociais e a percepção de futuro dos estudantes de licenciatura e analisar de que forma as repersentações desses estudantes estão postas.

\footnotetext{
${ }^{1}$ Entrevista a Jefferson Mainardes e Maria Inês Marcondes, realizada no dia 11 de setembro de 2007, ocasião em que os entrevistadores participavam da Reunião Anual da British Educational Research Association (BERA) - "Associação Britânica de Pesquisa Educacional" -, realizada no Instituto de Educação da Universidade de Londres. (MAINARDES; MARCONDES, 2009).

${ }^{2}$ FRANKEL, Boris. Los utopistas post-industriales. Buenos Aires: Ediciones Nueva Visión, 1987.
} 
ESTUDANTES DE LICENCIATURA NO BRASIL: representações sociais sobre o "ser professor no futuro"

\section{Políticas de formação de professores}

Com o pressuposto de que as políticas para a formação de professores são estabelecidas com base em um jogo de forças "[...] no âmbito das relações de poder, [...] constituídas pelos grupos econômicos e políticos, classes sociais e demais organizações da sociedade civil" (BONETI, 2012, p. 27), a par do fato de que o Estado se transformou, na maioria das vezes, em "um [...] agente repassador à sociedade civil das decisões saídas do âmbito da correlação de força travada entre os diversos segmentos sociais" (p. 27), admitimos que as mudanças não são gratuitas e que as transformações sociais e econômicas trazidas pelo capitalismo globalizado no presente decorrem da fluidez e de sua liquidez (BAUMAN, 2001). Tendo por foco essa "modernidade líquida", caracterizada pela volatilidade nas relações humanas, substituição do guia de coletividade e solidariedade pelo do individualismo e o transformar do cidadão em consumidor, ressaltamos as palavras de Ens et al. (2019, p. 264) quanto a que

[...] é preciso reconhecer que a legislação educacional brasileira não demonstra uma dinâmica previsível, por ser dependente de uma política internacional, em que os processos e dinâmicas situacionais/locais são ignorados ou rebaixados para um plano inferior.

Essa legislação a que nos referimos iniciou nos anos 1990, com a Lei de Diretrizes e Bases da Educação Nacional (LDB), Lei n. 9.396/1996 (BRASIL, 1996), bem como as que decorreram de sua proposta até o ano 2020, marcadamente orientadas em sua fase de produção pelos organismos internacionais, como: Banco Mundial (BM), Organização Mundial do Comércio (OMC), Organização das Nações Unidas para a Educação, a Ciência e a Cultura (UNESCO), Organização para a Cooperação e Desenvolvimento Econômico (OCDE), dentre outras, que atuam ora financiando ou orientando políticas globais e locais.

Essa questão é impulsionada na/pela ideologia neoliberal, como destacam Ens et al. (2016), porquanto movida pela globalização da economia mundial desde a década de 1970. O Brasil demonstra, no bojo de sua legislação sobre formação de professores, a solução para resolver os problemas de acesso e permanência dos estudantes na Educação Básica. Contudo, a proposta de formação do professor no Brasil não dá atenção às condições de trabalho e aos salários, apesar de o art. 67 da LDB n. 9.394/1996 indicar, para o magistério público, a "[...] valorização dos profissionais da educação, assegurandolhes, inclusive nos termos dos estatutos e dos planos de carreira” (BRASIL, 1996).

Pelo movimento das políticas educacionais brasileiras, verificamos que, por volta dos anos 1980, enfatizaram-se as matrículas na Escola Básica, e, nos anos 1990, havia a preocupação em combater a evasão escolar e garantir a permanência na escola. Por outro 
lado, a partir dos anos 2000, enfatiza-se a qualidade do ensino e da aprendizagem (CURITIBA, 2016).

Esses movimentos que ganharam força com a promulgação da Constituição da República Federativa do Brasil, de 1988, a qual em seu art. $6^{\circ}$ definiu a educação como um direito social, caracterizando-a na Seção I, do Capítulo III, nos artigos 205 a 216. Pelo art. 205, a educação passou a ser “[...] direito de todos e dever do Estado e da família, [... sendo] promovida e incentivada com a colaboração da sociedade, visando ao pleno desenvolvimento da pessoa, seu preparo para o exercício da cidadania e sua qualificação para o trabalho" (BRASIL, 1988).

Nos anos 2000, os professores, com outros profissionais que atuam no espaço escolar, passaram a ser denominados "profissionais da educação", e foi exigida a formação em nível superior para o exercício da docência na Educação Básica, a qual compreende: educação infantil, ensino fundamental I (anos iniciais, $1^{\circ}$ ao $5^{\circ}$ ano), ensino fundamental II (anos finais, $6^{\circ}$ ao $9^{\circ}$ ano) e ensino médio (última etapa da Educação Básica), etapa esta objeto da Lei n. 13.478/2017 e definida como exigência para ingresso na educação superior (BRASIL, 1996, 2017b).

A exigência de formação superior para o professor da Educação Básica passou por embates, sendo que em sua proposta inicial esta seria realizada em Institutos Superiores e/ou Escola Normal Superior, como definida pelo art. 62 da LDB, com redação definida pela Lei n. 13.415/2017:

[...] A formação de docentes para atuar na educação básica far-se-á em nível superior, em curso de licenciatura plena, admitida, como formação mínima para o exercício do magistério na educação infantil e nos cinco primeiros anos do ensino fundamental, a oferecida em nível médio, na modalidade normal. (BRASIL, 1996, 2017a).

O art. 61 da LDB também foi alterado pela Lei n. 13.415/2017, a qual incluiu nos incisos IV e $\mathrm{V}$ a condição de exercício profissional docente a outros profissionais "[...] com notório saber reconhecido pelos respectivos sistemas de ensino, para ministrar conteúdos de áreas afins à sua formação ou experiência profissional" (BRASIL, 1996, 2017b); isto é, sem formação específica profissional para o exercício do magistério.

Em relação àqueles que atuam na Educação Básica em áreas da não docência, a formação proposta foi expressa no artigo 64 da Lei de Diretrizes e Bases da Educação Nacional.

A formação de profissionais de educação para administração, planejamento, inspeção, supervisão e orientação educacional para a educação básica, será feita em cursos de graduação em pedagogia ou 
ESTUDANTES DE LICENCIATURA NO BRASIL: representações sociais sobre o "ser professor no futuro"

em nível de pós-graduação, a critério da instituição de ensino, garantida, nesta formação, a base comum nacional. (BRASIL, 1996).

Nesse contexto histórico, ganha resistência por parte dos professores e das associações voltadas à educação a Resolução CNE/CP n. 2/2019, porquanto passou a definir novas Diretrizes Curriculares Nacionais para a Formação Inicial de Professores para a Educação Básica e institui a Base Nacional Comum para a Formação Inicial de Professores da Educação Básica (BNC-Formação) que, em seu art. $2^{\circ}$, estabelece:

A formação docente pressupõe o desenvolvimento, pelo licenciando, das competências gerais previstas na BNCC-Educação Básica, bem como das aprendizagens essenciais a serem garantidas aos estudantes, quanto aos aspectos intelectual, físico, cultural, social e emocional de sua formação, tendo como perspectiva o desenvolvimento pleno das pessoas, visando à Educação Integral. (BRASIL, 2020)

Bem como estabeleceu, no art. $4^{\circ}$, as exigências a serem desenvolvidas na formação inicial docente:

As competências específicas se referem a três dimensões fundamentais, as quais, de modo interdependente e sem hierarquia, se integram e se complementam na ação docente. São elas:

I - Conhecimento profissional;

II - Prática profissional; e

III - engajamento profissional. (BRASIL, 2020)

Ademais, no parágrafo $3^{\circ}$, inciso I, do mesmo artigo, estabeleceu que o professor deve comprometer-se com as competências específicas da dimensão do engajamento profissional, sendo responsabilizado pelo próprio desenvolvimento profissional.

Sobre essa política, há um manifesto em defesa da permanência da Resolução CNE/CEP n. 2/2015, a qual definiu as Diretrizes Curriculares Nacionais para a formação inicial em nível superior (cursos de licenciatura, cursos de formação pedagógica para graduados e cursos de segunda licenciatura) e para a formação continuada, assinado por diversas entidades ${ }^{3}$ na Audiência Pública realizada, em 8 de outubro de 2019, sendo declarado que a política estabelecida pela Resolução CNE/CEP n. 2/2019:

[...] apresenta proposições que: destroem as políticas já instituídas; desconsideram a produção e o pensamento educacional brasileiro ao retomarem concepções ultrapassadas como a pedagogia das competências; apresentam uma visão restrita e instrumental de

\footnotetext{
3 ANFOPE; FORUMDIR; ANPEd; ABdC; SBEnBio; ABRAPEC; ANPUH; FINEDUCA; ANPAE; ANPOF; CUT; CEDES; CNTE; CONTEE; PROIFES; PARFOR/FORPARFOR; PIBID/FORPIBID-RP; MNDEM; SBEM; SBEnQ; UNCME; UNE; FNPE.
} 
docência e negativa dos professores; descaracterizam os núcleos formativos, a formação pedagógica e a segunda licenciatura; ignoram a diversidade nacional, a autonomia pedagógica das instituições formadoras e sua relação com a educação básica; relativizam a importância dos estágios supervisionados retrocedendo, desse modo, nos avanços que a área alcançou com a Resolução 02/2015. Repudiamos, também, a proposta de institucionalização de institutos superiores de educação, assim como a proposição de referenciais docentes de caráter meritocrático para a valorização do professor (formação, carreira, salário e condições de trabalho), entre tantas outras impropriedades. (BRASIL, 2020)

Sobre a definição da formação de professores de 2015, Dourado (2015) evidenciou a necessidade de instituição de um Sistema Nacional de Educação, que consolide a política de formação dos profissionais da educação, garanta os recursos oriundos da meta de $10 \%$ do PIB para a educação e estabeleça diretrizes para a carreira do magistério, entre outros processos, que propiciem melhorias na qualidade da educação no Brasil.

Ao refletirmos acerca de como dicotomias ou constantes sociais ancoram/transformam as políticas educacionais, bem como as representações sociais sobre futuro de "ser professor" de estudantes de licenciatura, participantes dessa pesquisa, temos, por convicção, que o "ser professor" tem transformado a prática do "ser professor" pelos “[...] novos papeis educativos, novos desafios que exigem estar atualizados sobre o que acontece no campo cientifico e social” (IMBERNÓN, 2016, p. 51); além da instalação da cultura da performatividade no interior da escola, a qual exige desempenho máximo de cada trabalhador. Esse processo está aliado às avaliações de seus alunos, aos rankings, que fazem o professor somar ao seu complexo trabalho de ensinar a incerteza e a instabilidade, as quais estão vinculadas, segundo Ball (2002, p. 10), a “[...] desempenhos excelentes, ou pelo menos credíveis, coletiva ou individualmente, em momentos de revisão, avaliação/apreciação e inspeção".

\section{Representações Sociais}

Refletir acerca das ações e perspectivas de um determinado grupo envolve conhecer como aqueles sujeitos constroem sua realidade, construção essa que entendemos a partir das suas representações, visto que "[...] possuem uma função constitutiva da realidade, pois, ao mesmo tempo em que elas preparam e orientam ações, elas também reconstituem os elementos do meio no qual as ações acontecem" (RICCI, 2007, p. 3).

As representações sociais sustentam a "preparação para a ação", pois determinam relações para o sujeito familiarizar-se com a realidade, consequentemente "[...] remodela 
ESTUDANTES DE LICENCIATURA NO BRASIL: representações sociais sobre o "ser professor no futuro"

e reconstitui os elementos do ambiente no qual o comportamento deve acontecer”(MOSCOVICI, 2012, p. 46). Para Marková (2006, p. 203), “[...] as representações sociais estão preocupadas com fenômenos especificamente definidos que precisam ser analiticamente descobertos".

Ao buscar a constituição de modelos com o intuito de intrepretarar a relação entre o indivíduo e a sociedade, Moscovici (2003, p. 10) criou uma teoria na qual destaca as representações sociais "[...] como uma forma característica de conhecimento em nossa era", considerando-as como um fenômeno, em vez de um conceito. Assim, as representações sociais “[...] carregam a 'marca desta tensão', conferindo sentido e assegurando a participação do sujeito no sistema, sem que sistema e sujeito se 'aniquilem' em consequência da tensão entre individualização e socialização" (CAMPOS; LOUREIRO, 2003, p. 13).

Aceitando a proposição de Moscovici (2003, p. 10) de que as representações sociais, por serem "[...] entidades quase tangíveis [que] circulam, se entrecruzam e se cristalizam continuamente, através duma palavra, dum gesto, ou duma reunião, em nosso mundo cotidiano", admitimos que elas fazem parte da maioria das relações que o(s) indivíduo(s) estabelece(m) com o seu contexto, presentes na parte simbólica da representação social, bem como, por outro lado, na prática que produz essa representação.

A partir dos desdobramentos da Teoria das Representações Sociais (TRS), desenvolvida por Moscovici, em 1961, dentre seus colaboradores europeus, Abric (2000) propôs a Teoria do Núcleo Central (TNC). Tal teoria, segundo Sá (1996, p. 62) permite desvelar os conteúdos de uma representação social “[...] sob a forma de uma hipótese a respeito da organização interna das representações sociais", pelos elementos que se distribuem em dois sistemas: sistema central (núcleo central) e o periférico. É, por meio desses sistemas, que se busca "[...] explicitar a lógica da estrutura encontrada, sua razão de ser - o que significa e o que justifica aquele núcleo central naquele grupo, e associado àqueles elementos periféricos" (ARRUDA, 2005, p. 233). Como Flament (2001, p. 175) esclarece, "[...] a teoria de Abric acrescenta a noção de centralidade qualitativa e estrutural, o núcleo central". O sistema periférico atualiza e contextualiza a representação no grupo investigado, "[...] assegurando o funcionamento quase instantâneo da representação como grade de decodificação" (FLAMENT, 2001, p. 177), funcionando qual "para-choque" (p. 178), entre “[...] uma realidade que a questiona e um núcleo central que não deve mudar facilmente" (p. 178).

As representações sociais sofrem modificações, tendo em vista a transfertilização de conjunturas, interesses e intenções e se constituir em representações individuais e coletivas. Conforme Guimelli (2003, p. 60), elas “[...] podem se modificar, mudar de estado, se transformar", por meio de práticas sociais que se transformam, oportunizando 
o surgimento de novas práticas. Para o autor:

[...] O processo de transformação das representações sociais toma formas diferentes, de acordo com o fato de as novas práticas estarem ou não em contradição com as representações antigas (Flament, 1989, 1993), mas também em função da maneira pela qual a modificação das circunstâncias é percebida: quando os sujeitos consideram que a mudança ocorrida em seu ambiente é irreversível, o processo de transformação das representações sociais parece irremediável. (GUIMELLI, 2003, p. 60. Grifos do autor).

Como exemplo, destacamos a produção dos dados que analisamos, coletados em 2018, anterior à data da promulgação das novas diretrizes para a formação inicial de professores (BRASIL, 2019).

\section{A pesquisa...}

Para a realização da presente pesquisa, fizemos uso do conceito de Hermenêutica Crítica, fundamentada em Gadamer (1997; 1998), relacionada à Teoria das Representações Sociais. A hermenêutica oportuniza, além da interpretação de textos teóricos, a interpretação da experiência do ser (RIBAS, 2017). Seibt (2016, p. 237) argumenta que não é possível "[...] separar sua interpretação do ato de interpretar a realidade e a si mesmo".

Gadamer (1997, p. 581) não desconsidera a teoria, mas discute a interpretação e a compreensão do fenômeno a partir da realidade social em consonância com a teoria, pois, para o autor, "[...] compreender e interpretar estão imbricados de modo indissolúvel", sendo necessário interpretar "[...] o que está por trás das palavras, expresso em gestos, atitudes, imerso em símbolos” (RIBAS, 2017, p. 30); uma vez que as pesquisas em representações sociais oportunizam analisar a subjetividade individual e grupal dos dados produzidos. Pois, como orienta Gonzàles Rey $(2006$, p. 70), não se trata de “[...] uma cópia, nem um reflexo do mundo real, é uma produção humana de caráter simbólico e de sentido que, dentro da 'realidade social' em que o homem vive [...]', esclarece o autor (Grifo do autor).

Refletir sobre o processo de formação do professor, bem como considerar as representações, os sentidos, os significados e a subjetividades, que o estudante de licenciatura atribui ao futuro do "ser professor", impacta diretamente no desenvolvimento de uma educação de qualidade social.

Para concretizar a interpretação crítica do fenômeno, em consonância com a elaboração da estrutura das representações sociais conforme a Teoria do Núcleo Central, 
ESTUDANTES DE LICENCIATURA NO BRASIL: representações sociais sobre o "ser professor no futuro"

optamos por utilizar os softwares Evoc ${ }^{4}$ (VERGÉS, 2002) e Iramuteq ${ }^{5}$ (RATINAUD, 2009). O uso dos softwares possibilitou a análise prototípica dos elementos que estruturam as representações sociais desse grupo de futuros professores, a partir das respostas ao teste de evocação livre de palavras com o termo indutor "ser professor no futuro" e a Classificação Hierárquica Descendente (CHD), pela análise lexical das justificativas à palavra mais importante na evocação livre.

A análise prototípica tem o intuito de identificar a estrutura da representação por meio de parâmetros de frequência e ordem da evocação de palavras (WACHELKE; WOLTER, 2011). A partir da organização dos dados, o software distribui esses dados em um quadro de quatro casas, agrupando-os por frequência e ordem média de evocações (OME). Essa distribuição possibilita identificar a estruturação das representações sociais por meio da análise prototípica, uma vez que os elementos ficam distribuídos entre o provável núcleo central (NC) e o sistema periférico da representação social analisada.

Já a CHD foi realizada com base na análise do agrupamento de palavras com raízes semânticas similares, representadas por um dendograma, cujo objetivo é ilustrar as relações interclasses. Dessa forma, o pesquisador identifica a importância de cada palavra na sua classe temática, segundo critérios estatísticos (CAMARGO; JUSTO, 2017).

\section{Transversalidade das representações sociais nas justificativas dos estudantes de licenciatura: futuro sobre "ser professor" e políticas docentes}

Os dados interpretados neste estudo foram gerados em uma instituição de ensino superior da rede privada, da qual participaram 80 estudantes de licenciaturas dos cursos de Letras e Pedagogia, em dois momentos. No primeiro momento, 43 estudantes de uma disciplina optativa ofertada para cursos de licenciatura em Pedagogia e Letras e, no momento seguinte, para 37 estudantes do segundo período do curso de Letras. Do total de estudantes participantes, 61 situam-se, entre 18 a 25 anos (76,25\%); aspecto que os caracteriza como jovens, de acordo com o IBGE (2010), 17 são maiores de 25 anos $(21,25 \%)$ e dois possuem menos de 18 anos (2,5\%), sendo a maioria estudantes de primeira graduação.

\footnotetext{
${ }^{4}$ Ensemble de programme permettant l'analyse des evocations.

${ }^{5}$ Interface de R pour les Analyses Multidimensionelles de Textes et de Questionnaires.
} 


\section{Análise Prototípica - Ordem Média de Evocações (OME)}

Dos 80 participantes, apenas um não atendeu à instrução de escrever as cinco primeiras palavras que lhe ocorressem como complementação ao indutor "Ser professor no futuro". O total de respostas coletadas foi de 398, destas 159 diferentes. Após a lematização, o corpus para análise ficou reduzido a 140 termos. Os critérios para rodar o programa Tabrgrf do software (EVOC, 2005), que informa a distribuição dos "termos evocados em quatro quadrantes, que correspondem à estrutura da representação estudada" (OLIVEIRA et al., 2005, p. 584), foram: frequência mínima 4, frequência intermediária 8 e 3 de ordem média. Os procedimentos descritos pela autora para rodar o Evoc foram adotados.

Dos 27 elementos que atenderam aos critérios de corte $(f\rangle=<8$; OM 3), a maioria se localizou na Zona de Contraste ( $3^{\circ}$ quadrante), indicando a "face escondida" da representação, a qual, é “[...] constituída pelos elementos da representação que têm um caráter contranormativo" (ABRIC, 2005, p. 24-25. Grifo do autor).

Ao consideramos os dados produzidos nessa pesquisa, a partir da análise prototípica (QUADRO 1) com a frequência $(f)$ e a ordem média das evocações (OME) das palavras prontamente evocadas, os vocábulos "incerteza", "profissão", "realização", "sucesso", "tecnologia" e "trabalho", face aos critérios de corte adotados, foram os que constituíram o provável núcleo central $(\mathrm{NC})$ da RS "Ser professor no futuro". A nosso ver, tais elementos expressam dimensões das diferentes "camadas contextuais [...de] diferentes no tempo e no espaço, podendo ir do passado ao presente, da história à circunstância, numa espiral de planos e passos" (ARRUDA, 2005, p. 234-235) dos participantes, envoltos pelas decorrências das problemáticas sócio/políticas e financeiras e das macro gestadas pelos poderes públicos e a sociedade brasileira.

Em decorrências de que o trabalho do professor está ancorado em inquietações e incertezas para a realização profissional, estas parecem habitar o centro da RS "ser professor no futuro". Contudo, vivenciam um misto de "incerteza" e de sentimentos de "realização", ligados ao possível "sucesso", como que debilita o que esses estudantes de licenciatura demonstram sentir ligados à "família", à "felicidade", ao "dinheiro", oportunidades de viajarem e à "estabilidade" que o ser professor oportunizará a esses futuros profissionais. Observe-se que o sentimento de "amor" foi o que obteve frequência menor (9) nesse quadrante ( $1^{\mathrm{a}}$ periferia). Como elementos periféricos mais importantes da RS, tais palavras/elementos dão sentido ao "sucesso" e à "realização" que os participantes anteveem para seu futuro como professores, apesar de suas incertezas (NC), de seus "sonhos" e de seu "medo" (3 quadrante, QUADRO 1). 
ESTUDANTES DE LICENCIATURA NO BRASIL: representações sociais sobre o "ser

professor no futuro"

Quadro 1 - Estrutura e organização da RS dos estudantes sobre "Ser professor no futuro" na situação de resposta de evocação inicial (OME).

\begin{tabular}{|c|c|c|c|c|c|c|c|}
\hline $\begin{array}{l}\text { PONTO DE } \\
\text { CORTE }\end{array}$ & $\begin{array}{l}\text { VOCABULOS } \\
\text { /ELEMENTOS }\end{array}$ & \multicolumn{2}{|c|}{ OME } & $\begin{array}{l}\text { PONTO DE } \\
\text { CORTE }\end{array}$ & $\begin{array}{l}\text { VOCABULOS/ } \\
\text { ELEMENTOS }\end{array}$ & \multicolumn{2}{|c|}{ OME } \\
\hline \multirow{7}{*}{$\begin{array}{c}\text { Freg }>=8 \\
\mathrm{OM}=3\end{array}$} & \multicolumn{3}{|c|}{$\begin{array}{c}I^{\circ} \text { Quadrante } \\
\text { Provável Núcleo Central }\end{array}$} & \multirow{7}{*}{$\begin{array}{c}\text { Freg }>=8 \\
\mathrm{OM}<3\end{array}$} & \multicolumn{3}{|c|}{$\begin{array}{c}2^{\circ} \text { Quadrante } \\
1^{2} \text { Periferia }\end{array}$} \\
\hline & Incerteza & 10 & 2,20 & & Amor & 9 & 4,00 \\
\hline & Profissão & 8 & 2,75 & & Dinheiro & 19 & 3,10 \\
\hline & Realização & 10 & 2,50 & & Estabilidade & 12 & 3,15 \\
\hline & Sucesso & 15 & 2,87 & & Família & 27 & 3,11 \\
\hline & Tecnologia & 9 & 2,00 & & Felicidade & 20 & 3,50 \\
\hline & Trabalho & 9 & 2,22 & & Viagem & 13 & 3,69 \\
\hline \multirow{10}{*}{$\begin{array}{l}\text { Freg }=8 \\
O M<=3\end{array}$} & $\begin{array}{r}30 \text { Quad } \\
\text { Zona de C }\end{array}$ & & & \multirow{10}{*}{$\begin{array}{l}\text { Freg }<8 \\
\mathrm{OM}>=3\end{array}$} & \multicolumn{3}{|c|}{$\begin{array}{c}4^{\circ} \text { Quadrante } \\
2^{2} \text { Periferia }\end{array}$} \\
\hline & Carro & 7 & 2,71 & & Carreira & 6 & 3,33 \\
\hline & Educação & 4 & 2,50 & & Conquista & 4 & 4,25 \\
\hline & Emprego & 7 & 1,86 & & Estudos & 5 & 3,20 \\
\hline & Esperança & 4 & 1,75 & & Mudança & 6 & 3,67 \\
\hline & Formação & 6 & 2,68 & & Paz & 4 & 3,25 \\
\hline & Liberdade & 5 & 2,40 & & Responsabilicade & 4 & 4,75 \\
\hline & Medo & 4 & 3,00 & & & & \\
\hline & Professor & 6 & 1,67 & & & & \\
\hline & Sonhos & 5 & 2,80 & & & & \\
\hline
\end{tabular}

Fonte: os autores (2019). Obs.: $f=$ frequência; OM = Ordem média.

No embate cotidiano com o trabalho, os professores sofrem tensões e incertezas provocadas pela reestruturação do que devem cumprir profissionalmente para atenderem às reformas educacionais (COSME, 2011), no que corroboram Ens e Donato (2011, p. 86), destacando que vários autores "[...] alertam que as reformas educacionais das últimas décadas têm repercutido no trabalho do professor ao provocar uma reestruturação no trabalho docente". Esses novos modos de regulação educacional, afirmam as autoras, se expressam, principalmente devido "[...] a disputa entre uma política educacional neoliberal e a uma política humanista-igualitária..." (p. 86). Tais regulações criam um mal-estar no exercício, o que pode ter sido sentido pelos participantes ao longo de suas experiências escolares; talvez, por isso, suas incertezas e medo quanto a serem professores. Como pontua Ferreira (2013, p. 266), "Os conflitos da condição docente se aprofundaram devido ao aumento da sua precariedade com as questões salariais não equacionadas, as tensões da rotina do trabalho permeadas pelas dificuldades sociais, culturais econômicas da maioria da população estudantil.”. Tais condições, quando submetidas a um "[...] exame das políticas educacionais implantadas [...] revela que convivemos com a tradicional política de governos que buscam driblar os conflitos mundial e nacional sob a lógica do capital” (p. 266). 
É preciso estar atento para o fato de que "[...] as representações se transformam mais lentamente do que as oscilações das realidades sociais, políticas e econômicas" (OLIVEIRA et. al., 2005, p. 599). Se de um lado, a análise prototípica das evocações auxilia em muito o processo de captar os conceitos preconcebidos, preocupações e lacunas, que podem existir entre o que os participantes pensam acerca de "Ser professor no futuro"; de outro, a análise dos dados textuais produzidos pelos participantes pode induzir para outras questões que trespassam essa RS.

\section{Análise da Classificação Hierárquica Descendente - CHD}

Para essa análise, utilizamos o material linguístico das 80 justificativas (L.1 a L.80) dadas para a palavra definida como mais importante das evocações livres ao termo indutor "Ser professor no futuro", compondo o Dendograma apresentado na Figura 1.

Figura 1 - Dendograma Classificação Hierárquica Descendente (CHD) com as respectivas classes temáticas

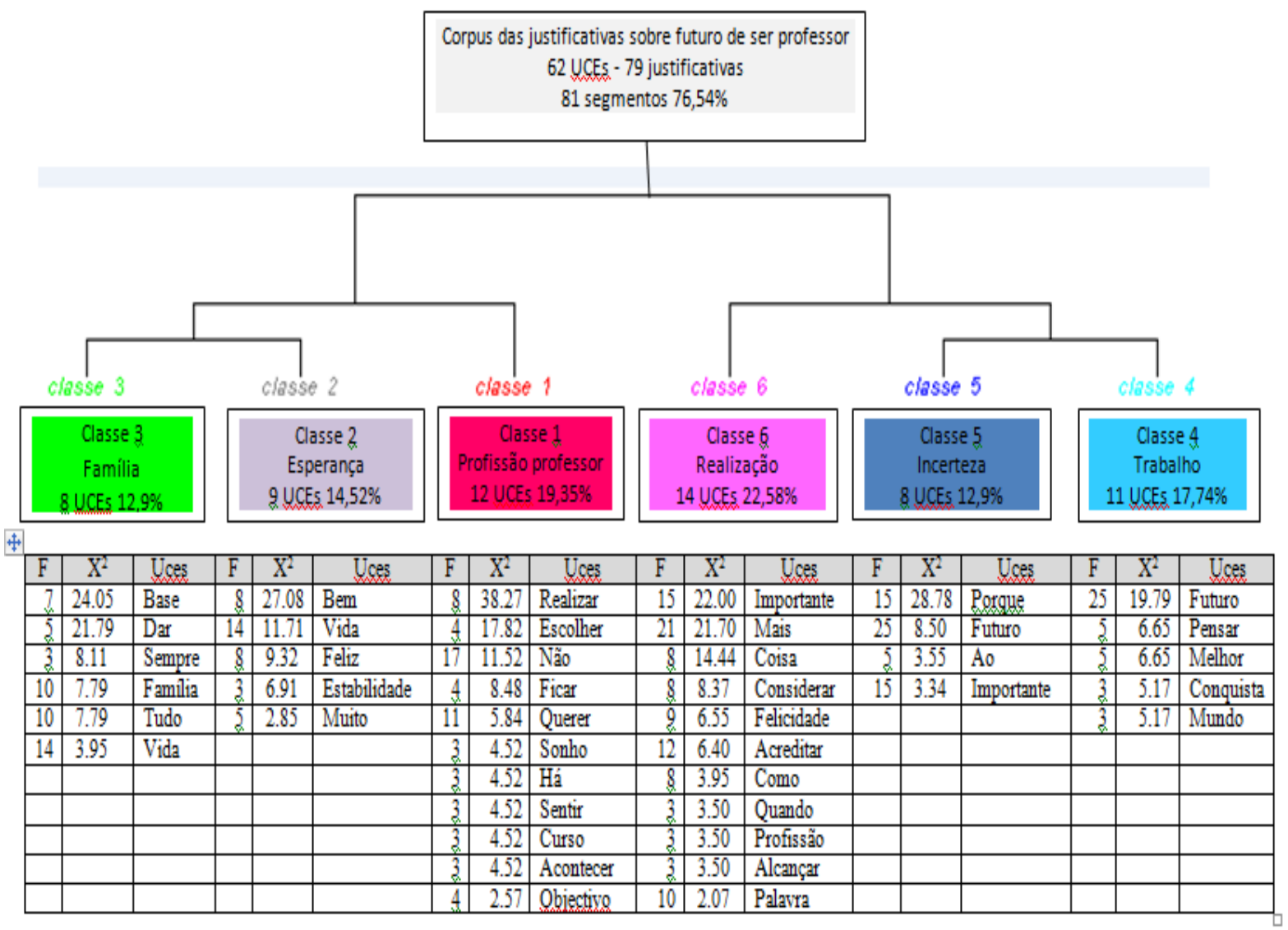

Fonte: os autores (2019). 
ESTUDANTES DE LICENCIATURA NO BRASIL: representações sociais sobre o "ser professor no futuro"

A leitura do Dendograma ${ }^{6}$ (FIGURA 1) permite identificar que a estrutura hierárquica das seis classes temáticas agrupa dois blocos/segmentos (A e B). O bloco A aglutina os léxicos das classes 4 (Trabalho) e da classe 5 (Incerteza), com léxicos relacionados à classe 6 (Realização), e o bloco $\mathrm{B}$, com os léxicos da classe 1 (Profíssão professor), com léxicos relacionados à classe 2 (Esperança) e à classe 3 (Família).

Em relação ao aproveitamento de segmentos de UCEs, as classes 4 (17,74\%), a 5 $(12,9 \%)$ e a $6(22,58 \%)$, que representam o bloco A, respondem por $53,22 \%$ do corpus analisado; ou seja, $33(11+8+14)$ das 62 UCEs das justificativas classificadas pelo software. A presença de um maior número de segmentos relacionados às justificativas, que utilizam as classes como aglutinadora de léxicos referentes a "Ser professor no futuro", como - trabalho, incerteza e realização - indicam-nos que os estudantes ancoram suas representações nas constantes políticas que definem sua formação e o futuro de seu complexo trabalho.

A classe 6, categorizada como realização, ao ser entendida no sentido de alcançar sucesso, satisfação, paz, amor, significa que os futuros professores possuem expectativas articuladas à realização no trabalho docente e diversas perspectivas de vida. Justificam: "acredito que todas essas palavras são importantes e todas têm relações uma com a outra, acho que satisfação seria a mais importante e a que prego no momento uma satisfação como pessoa na vida profissional e pessoal" (L.54); e "a palavra que considero mais importante é estabilidade, a estabilidade a qual me refiro e a estabilidade emocional financeira e da saúde; acredito que com estabilidade consigo alcançar todos os outros objetivos" (L.40).

As classes 4 (Trabalho) e 5 (Incertezas) retratam incertezas sobre o futuro, mas acreditam que o conhecimento sobre o trabalho possibilita superar as incertezas como justificam os estudantes: "quando penso no futuro acredito que o conhecimento sobre mim, os outros e o mundo será a base para adquirir os outros aspectos; as outras palavras, penso que quanto mais se sabe ou quando se descobre o quanto não se sabe nós elaboramos e crescemos" (J.67); e "porque o futuro é inesperado pelo fato de muitas vezes as coisas não acontecerem como previmos ou planejamos" (J.43).

O bloco B, constituído pelas classes 1, 2 e 3, relacionadas à Profissão professor, Esperança e Família. A classe 1, categorizada "Profissão professor", ancora-se no planejar, define objetivos e executar, como justificam os estudantes 61 e 62: "sem traçarmos um objetivo não chegaremos a lugar algum" (L.61); "nada adianta estar com um diploma em mãos e não me sentir feliz e realizado com o curso que eu escolhi” (L.62).

\footnotetext{
${ }^{6}$ Para a leitura de um dendograma, De Alba (2004) sugere que esta seja realizada da direita para a esquerda ou de cima para baixo, quando disponibilizado verticalmente.
} 
A classe 2 (Esperança) relaciona-se com a transformação de si e com superação, como justifica o estudante 32: "é o destaque no emprego que vai me levar aos outros principalmente em termos de carreira profissional e financeiros" (L.32). Acreditam que a formação na licenciatura, apesar das incertezas, pode significar uma possibilidade de superação das suas condições históricas. E, a classe 3 (Família) retrata a esfera de pertença "intersubjetiva" dos entes familiares, que justificam o esforço em cursar uma faculdade; bem como destaca o bem-estar que essa formação superior pode fornecer para eles, assim como a segurança que pode representar para que constituam suas próprias famílias. Justificam: "a família é a base de minha vida espero continuar dando orgulho aos meus pais" (L.28), e "eu quero ter muito sucesso em minha carreira para que ela seja promissora e, então, o emprego estável para ter uma vida tranquila, para que eu possa constituir uma família e dar tudo do bom e do melhor para eles, inclusive uma educação de qualidade" (L.16).

Podemos dizer que as representações que emergem desse grupo de estudantes de licenciatura, na sua grande maioria, constituem uma baixa classe média, que incide em optar em cursar uma faculdade, mesmo não tendo garantias concretas de sucesso. Pois, compreendem as precárias condições de trabalho na escola, os baixos salários e a desvalorização dos professores, que são aspectos que os fazem enfrentarem situações de tensão. Acreditam que podem superar as condições sociais, culturais e econômicas, que lhes foram impostas historicamente e às suas famílias pela possibilidade de ascensão via trabalho/profissão docente.

Já, em 2009, Gatti e Barreto (2009, p. 164) apresentaram o perfil socioeconômico dos estudantes de licenciatura no Brasil, como “[...] um grupo majoritário (50,4\%) que se concentra nas faixas de renda familiar média, cujo intervalo é de três a dez saláriosmínimos", sendo significativo "[...] o percentual de alunos com renda familiar de até três salários-mínimos (39,2\%), e escassa a frequência de sujeitos nas faixas mais elevadas de renda" (p. 164).

Destacamos que, em 2016, por exemplo, a relação anual de informações sociais (Rais) demonstrou que existiam 3.294.788 postos de trabalho para professores e outros profissionais de ensino (BRASIL, 2016), ocupados por profissionais já formados ou por estudantes de licenciatura. Aspectos, nos quais, parecem-nos ancoradas as representações que retratam o desenho da demanda por professores da Educação Básica no Brasil, principalmente na pública, o que proporciona muitas contratações, seja por concurso público ou por outras formas mais precarizadas de vínculo; além de poder explicar as representações sociais desse grupo de estudantes que encontra na formação de professores uma possibilidade de mobilidade social. 
ESTUDANTES DE LICENCIATURA NO BRASIL: representações sociais sobre o "ser professor no futuro"

\section{Interpretando e questionando...}

O campo de pesquisa das RS apresenta "[...] três particularidades marcantes: vitalidade, transversalidade e complexidade" (JODELET, 2001, p. 23). O que nos possibilitou inferir os questionamentos e as incertezas acerca do "ser professor" de estudantes em formação inicial, ao serem instruídos e formados para atuarem com novas gerações.

Esse processo, para Sousa (2017), precisa ser significativo, e envolver reflexões críticas acerca do contexto de formação e atuação em que está ou virá a ser inserido, objetivando formar-se a partir do comprometimento com a qualidade da educação, com base em um ambiente de formação recíproca de valores como liberdade, direito e justiça social. Ou seja, oferecer mais do que indicam as políticas educacionais para que compreendam o papel social que exercem na sociedade e na ação docente.

Sobre esse contexto, Evangelista e Shiroma (2007, p. 537) alertam que as reformas neoliberais sobre formação de professores, ao atingirem “[...] todas as esferas da docência: currículo, livro didático, formação inicial e contínua, carreira, certificação, lócus de formação, uso das tecnologias da informação e comunicação, avaliação e gestão", contribuem para a precarização, a intensificação do trabalho e o alargamento das funções docentes.

Essas políticas, segundo Shiroma, Campos e Garcia (2005, p. 436), apoiadas em Ball $^{7}$ (1994, p. 16), “[...] são produtos de compromissos nos vários estágios, na micropolítica da formulação da legislação no debate entre parlamentares e na micropolítica da articulação dos grupos de interesse". Esse aspecto tem contribuído para que os estudantes do estrato mais baixo da população encontrem na carreira docente uma possibilidade de ascensão econômica, cultural e social, de forma dicotômica, como afirmam Gatti e Barreto (2009). São representações sociais, quanto ao futuro profissional, que ancoram no ser professor espaços esperançosos de ascenderem a estratos populacionais em que encontrarão melhores condições econômicas, sociais e culturais, com a compreensão quanto aos aspectos de incertezas e de desvalorização articulados ao exercício profissional docente no Brasil. Pois, “[...] o pensamento do formar para quêe por quê recoloca os formadores de professores e aos próprios professores em formação no caminho da prática social da busca de sentido, da luta por uma qualidade de educação" (SOUSA, 2017, 745. Grifo da autora).

Os dados produzidos possibilitaram a interpretação dialógica das relações dos

\footnotetext{
${ }^{7}$ Shiroma, Campos e Garcia (2005) discutem a concepção de política, com base na obra de Stephen J. BALL. Education reform. A critical and post-structural approach, publicada em Buckingham, pela Open University Press, em 1994.
} 
elementos que constituem a estrutura e organização da RS dos estudantes sobre "Ser professor no futuro", somada às intraclasses e interclasses que a constituem e exemplificam parte do universo transubjetivo que sustenta as representações dos estudantes de licenciatura.

\section{Referências}

ABRIC, J. C. A abordagem estrutural das representações sociais. In: MOREIRA, Antonia Silva Paredes; OLIVEIRA, Denize Cristina (Org.). Estudos interdisciplinares de representação social. Goiânia: AB, 2000. p. 27-38.

ABRIC, J. C. A zona muda das representações sociais. In: OLIVEIRA, Denise Cristina de; CAMPOS, Pedro Humberto Faria. Representações sociais, uma teoria sem fronteiras. Rio de Janeiro: Museu da República, 2005. p. 23-34.

ANDRÉ, M. Formação de professores: a constituição de um campo de estudos. Revista Educação, Porto Alegre, RS, v. 33, n. 3, p. 174-181, set./dez. 2010.

ARRUDA, A. Despertando do pesadelo: a interpretação. In: MOREIRA, Antonia Silva Paredes. Perspectivas teórico-metodológicas em representações sociais. João Pessoa: Ed. Universitária da UFPB, 2005. p. 229-258.

BALL, S. J. Reformar escolas/reformar professores e os terrores da performatividade. Revista Portuguesa de Educação, Braga, Portugal, v. 15, n. 2, p. 3-23, 2002.

BAUMAN, Z. Modernidade líquida. Trad. Plínio Dentzien. Rio de Janeiro: Zahar, 2001.

BONETI, L. W. As políticas públicas no contexto do capitalismo globalizado: da razão moderna à insurgência de processos e agentes sociais novos. PRACS: Revista Eletrônica de Humanidades do Curso de Ciências Sociais da UNIFAP. Macapá, n. 5, p. 17-28, dez. 2012.

BRASIL. Conselho Nacional de Educação. Conselho Pleno. Resolução CNE/CP n ${ }^{\circ}$ 2, de 20 de dezembro de 2019. Define as Diretrizes Curriculares Nacionais para a Formação Inicial de Professores para a Educação Básica e institui a Base Nacional Comum para a Formação Inicial de Professores da Educação Básica (BNC-Formação). Republicada por ter saído com incorreção no DOU de 10-2-2020, Seção 1, páginas 87-90. Incorpora as correções aprovadas na Sessão Extraordinária do Conselho Pleno, realizada no dia 11- 32020. Diário Oficial da União, Brasília, DF, 10 fev. 2020, Seção 1, p. 87-90. Disponível em: http://portal.mec.gov.br/index.php?option=com docman\&view=download\&alias= 135951-rcp002-19\&category_slug=dezembro-2019-pdf\&Itemid=30192. Acesso em: 11 fev. 2020. 
BRASIL. Constituição da República Federativa do Brasil. Diário Oficial da União, Brasília, DF, 05 out.1988. p.1 (Anexo). Disponível em: https://www.planalto.gov.br/ ccivil_03/Constituicao/Constituiçao.htm. Acesso em: 22 jan. 2019.

BRASIL. Ministério do Trabalho e Emprego. Programa de Disseminação das Estatísticas do Trabalho. Relação Anual de Informações Sociais (RAIS). Brasília, DF, 2016. Disponível em: http://portalfat.mte.gov.br/programas-e-acoes-2/relacao-anual-deinformacoes-sociais-rais/. Acesso em: 28 fev. 2020.

BRASIL. Presidência da República. Lei n. ${ }^{\circ} 13.415$ de 16 de fevereiro de 2017. Altera as Leis nos 9.394, de 20 de dezembro de 1996, que estabelece as diretrizes e bases da educação nacional, e 11.494, de 20 de junho 2007, que regulamenta o Fundo de Manutenção e Desenvolvimento da Educação Básica e de Valorização dos Profissionais da Educação, a Consolidação das Leis do Trabalho - CLT, aprovada pelo Decreto-Lei n. ${ }^{\circ}$ 5.452, de $1^{\circ}$ de maio de 1943, e o Decreto-Lei $n^{\circ} 236$, de 28 de fevereiro de 1967; revoga a Lei $n^{\circ}$ 11.161, de 5 de agosto de 2005; e institui a Política de Fomento à Implementação de Escolas de Ensino Médio em Tempo Integral. Diário Oficial da União, Poder Legislativo, Brasília, DF, 17 de fev. de 2017a. Disponível em: http://www.planalto.gov. br/ccivil_03/_Ato2015-2018/2016/Mpv/mpv746.htm\#art1. Acesso em: 20 nov. 2019.

BRASIL. Presidência da República. Lei no 13.478, de 30 de agosto de 2017. Altera a Lei n ${ }^{\circ}$ 9.394, de 20 de dezembro de 1996 (Lei de Diretrizes e Bases da Educação Nacional), para estabelecer direito de acesso aos profissionais do magistério a cursos de formação de professores, por meio de processo seletivo diferenciado. Diário Oficial da União, Brasília, DF, 31 ago. 2017b. Disponível em: http://www.planalto.gov.br/ccivil03/ Ato2015-2018/2017/Lei/L13478.htm. Acesso em: 20 nov. 2019.

BRASIL. Presidência da República. Lei n. ${ }^{\circ}$ 9.394, de 20 de dezembro de 1996. Estabelece as diretrizes e bases da educação nacional. Diário Oficial da União, Brasília, DF, 23 dez. 1996. Disponível em: http://www.planalto.gov.br/ccivil_03/Leis/L9394.htm. Acesso em: 20 nov. 2019.

CAMARGO, B. V.; JUSTO, A. M. Tutorial para uso do software de análise: (Interface de R pour les Analyses Multidimensionnelles de Textes et de Questionnaires). 2017.

CAMPOS, P. H. F.; LOUREIRO, M. C. da S. Representações sociais e práticas educativas. Goiânia, GO: Ed. da UCG, 2003.

COSME, A. Ser professor numa escola e num tempo de incertezas. In: ENS, Romilda T.; BEHERENS, Marilda A. (Org.). Ser professor: formação e os desafios na docência. Curitiba: Champagnat, 2011. p. 27-53.

CURITIBA. Prefeitura Municipal. Secretaria Municipal da Educação. Caderno Pedagógico - Caderno de avaliação do Projeto Equidade. 2016. 
DE ALBA, M. El método Alceste e y su aplicación al estudio de las representaciones sociales del espacio urbano: el caso de la ciudad de México. Papers on Social Representations, v.13, p.1.1 - 1.20, 2004.

DOTTA, L. T. Representações sociais do ser professor. Campinas, SP: Editora Alínea, 2006.

DOURADO, L. F. Diretrizes Curriculares Nacionais para a formação inicial e continuada dos profissionais do magistério da educação básica: concepções e desafios. Educação $e$ Sociedade, Campinas, SP, v. 36, n. 131, p. 299-324, abr./jun., 2015.

ENS, R. T.; DONATO, S. P. Ser professor e formar professores: tensões e incertezas contemporâneas. In: ENS, R.; BEHERENS, M. A. (Org.). Ser professor: formação e os desafios na docência. Curitiba: Champagnat, 2011. p. 79-100.

ENS, R. T. et al. Política educacional: participação democrática no plano municipal de educação de Curitiba. Revista Interacções, Lisboa, n. 40, p. 89-109, 2016.

ENS, R. T. et al. Valorização do professor: prioridade política, tensão ou incerteza? Cadernos de Pesquisa, São Paulo, v. 49, n. 172, p. 260-283, abr./jun. 2019.

EVANGELISTA, O.; SHIROMA, E. O. Professor: protagonista e obstáculo da reforma. Educação e Pesquisa, São Paulo, v. 33, n. 3, p. 531-541, set./dez. 2007.

EVANGELISTA, O.; TRICHES, J. Curso de Pedagogia, organizações multilaterais e o superprofessor. Educar em Revista, Curitiba, v.28, n.45, p.185-198, jul/set. 2012. http://dx.doi.org/10.1590/S0104-40602012000300013

FERREIRA, E. B. Políticas educativas no Brasil no tempo da crise. In: FERREIRA, Eliza Bartolozzi; OLIVEIRA, Dalila Andrade. (Org.). Crise da escola e políticas educativas. 2. ed. Belo Horizonte: Autêntica, 2013. p. 253-270.

FLAMENT, C. Estrutura e dinâmica das representações sociais. In: JODELET, Denise. (Org.). As representações sociais. Trad. Lilian Ulup. Rio de Janeiro: Ed. UERJ, 2001. p. 173-186.

GADAMER, H. G. O problema da consciência histórica. Pierre Fruchon (Org.). Trad. Paulo Cesar Duque Estrada. Rio de Janeiro: Editora FGV, 1998.

GADAMER, H. G. Verdade e método: traços fundamentais de uma hermenêutica filosófica. Trad. Flávio Paulo Meurer. 3. ed. Petrópolis, RJ: Vozes, 1997.

GATTI, B. A.; BARRETO, E. S. de S. Professores do Brasil: impasses e desafios. Brasília, DF: UNESCO/MEC, 2009.

GONZÁLEZ REY, F. L. As representações sociais como produção subjetiva: seu impacto na hipertensão e no câncer. Psicologia: Teoria e Prática, São Paulo, v. 8, n. 2, p. 69-85, 2006. 
ESTUDANTES DE LICENCIATURA NO BRASIL: representações sociais sobre o "ser professor no futuro"

GUIMELLI, C. Transformação das representações sociais, novas práticas e esquemas cognitivos de base. In: CAMPOS, Pedro Humberto F.; LOUREIRO, Marcos Corrêa da S. Representações sociais e práticas educativas. Goiânia, GO: Ed. da UCG, 2003. p. 5980 .

HARTOG, F. Regimes de historicidade: presentismo e experiências do tempo. Trad. Andréa S. de Menezes, Bruna Beffart, Camila R. Moraes, Maria Cristina de A. Silva e Maria Helena Martins. 1. ed., 2. reimpr. Belo Horizonte: Autêntica, 2015.

IBGE. População jovem do Brasil. Censo de 2010. Disponível em: https://ww2.ibge.gov.br/home/estatistica/populacao/populacao_jovem_brasil/default.sht m. Acesso em: 10 fev. 2018.

IMBERNÓN, F. Qualidade do ensino e formação do professorado: uma mudança necessária. Cortez: São Paulo, 2016.

JODELET, D. Representações sociais: um domínio em expansão. In: JODELET, D. (Org.). As representações sociais. Tradução Lilian Ulup. Rio de Janeiro: Eduerj, 2001. p. 17-44.

MAINARDES, J; MARCONDES, M. I. Entrevista com Stephen J. Ball: um diálogo sobre justiça social, pesquisa e política educacional. Educação e Sociedade, Campinas, SP, v. 30, n. 106, p. 303-318, jan./abr. 2009.

MARKOVÁ, I. Dialogicidade e representações sociais: as dinâmicas da mente. Tradução Hélio Magri Filho. Petrópolis, RJ: Vozes, 2006.

MOSCOVICI, S. A psicanálise, sua imagem e seu público. Tradução Sonia Fuhrmann. Petrópolis, RJ: Vozes, 2012.

MOSCOVICI, S. Representações sociais: investigações em psicologia social. Tradução Pedrinho A. Guareschi. Petrópolis. RJ: Vozes, 2003.

OLIVEIRA, D. C. de et al. Análise das evocações livres; uma técnica de análise estrutural das representações sociais. In: MOREIRA, Antonia Silva P. et al. Perspectivas teóricometodológicas em representações sociais. João Pessoa: Ed. UFPB, 2005. p. 573-603.

RATINAUD, P. IRAMUTEQ: Interface de R pour les Analyses Multidimensionnelles de Textes et de Questionnaires [software]. 2009. Disponível em: http://www.iramuteq.org. Acesso em: 20 dez. 2019.

RIBAS, M. S. Educação em Direitos Humanos no contexto da Educação de Jovens e Adultos: o desvelar da violência simbólica. 226f. Tese (Doutorado em Educação) Pontifícia Universidade Católica do Paraná, Curitiba, 2017.

RICCI, A. Representações sobre o processo de ensino-aprendizagem de língua inglesa dos alunos da $5^{a}$ a $8^{a}$ séries de uma escola pública do Estado de São Paulo. $2007.117 \mathrm{f}$. 
Dissertação (Mestrado em Linguística) - Pontifícia Universidade Católica de São Paulo, São Paulo, 2007.

SEIBT, C. L. Dupla estrutura do conhecimento em Heidegger: explicar é compreender. PERI Revista de Filosofia, Florianópolis, v. 8, n. 1, p. 230-241, 2016.

SHIROMA, E. O.; CAMPOS, R. F.; GARCIA, R. M. C. Decifrar textos para compreender a política: subsídios teórico-metodologógicos para análise de documentos. Perspectiva - Revista do Centro de Ciências da Educação da UFSC, Florianópolis, v. 23, p. 427-446, 2005.

SOUSA, C. P. de. Desafios da formação de professores. Diálogo Educacional. Curitiba, v. 17, n. 53, p. 739-756, 2017.

WACHELKE, J.; WOLTER, R. Critérios de construção e relato da análise prototípica para representações sociais. Psicologia: teoria e pesquisa. Brasília, DF, v. 27, n. 4, 2011. p. 521-526.

VÈRGES, P. Conjunto de programas que permitem a análise de evocações: EVOC: manual. Versão 5. Aix en Provence: [S. n.], 2002.

Recebido em: 21 mar. 2020. Aprovado em: 11 jun. 2020.

* Romilda Teodora Ens é Doutora em Educação: Psicologia da Educação pela PUCSP. PósDoutora em Educação pela Universidade do Porto-Portugal. Professora Titular do Programa de Pós-Graduação em Educação da PUCPR. Pesquisadora Produtividade pela Fundação Araucária - Paraná. Líder do Grupo de Pesquisa Políticas, Formação de Professores, Trabalho Docente e Representações Sociais da PUCPR.

E-mail: romilda.ens@gmail.com.

https://orcid.org/0000-0003-3316-1014.

** Jaqueline Salanek de Oliveira Nagel é Doutoranda do curso de Pós-Graduação em Educação, Linha de História e Políticas da Educação pela PUCPR. Professora Pedagoga da Rede Municipal de Ensino de Curitiba/PR, Membro do Grupo de Pesquisa Políticas, Formação de Professores, Trabalho Docente e Representações Sociais da PUCPR.

E-mail: jaquenagel@gmail.com.

https://orcid.org/0000-0002-2537-4215 
ESTUDANTES DE LICENCIATURA NO BRASIL: representações sociais sobre o "ser professor no futuro"

*** Thalita Vianna de Lima é Mestranda do curso de Pós-Graduação em Educação, na Linha de História e Políticas da Educação pela PUCPR. Professora do Colégio Medianeira, CuritibaPR. Membro do Grupo de Pesquisa Políticas, Formação de Professores, Trabalho Docente e Representações Sociais da PUCPR.

E-mail: thalita.vianna17@hotmail.com .

https://orcid.org/0000-0003-1977-5300.

**** Cassiano Roberto Nascimento Ogliari é Doutor em Educação: História, Política, Sociedade pela PUCSP. Pós-doutorando em Educação e Mestre em Educação pela PUCPR. Licenciado em Pedagogia e Matemática com especialização em Metodologia do Ensino de Matemática. Professor da Rede Estadual de Educação do Paraná. Membro do Grupo de Pesquisa: Políticas, Formação de Professores e Representações Sociais (POFORS) na PUCPR.

E-mail: cassianoogliari@gmail.com.

http://orcid.org/0000-0002-4304-9539. 